\title{
Effects of Magnetically Treated Sedum Alfredii Seeds On The Dissolved Organic Matter Characteristics of Cd-Contaminated Soil During Phytoextraction
}

\author{
Youjun Tang \\ Yangtze University \\ Shuaizhi Ji \\ sinopec Zhongyuan oilfield \\ Dan Chen \\ Yangtze University \\ Jiawei Wang \\ Yangtze University \\ Min Cao \\ University of Leicester \\ Jie Luo ( $\square$ gchero1216@hotmail.com ) \\ Yangtze University https://orcid.org/0000-0001-6543-9346
}

\section{Research Article}

Keywords: Phytoextraction, Sedum alfredii, Magnetic field, Dissolved organic matter, Rhizosphere

Posted Date: June 22nd, 2021

DOl: https://doi.org/10.21203/rs.3.rs-560215/v1

License: (c) (1) This work is licensed under a Creative Commons Attribution 4.0 International License.

Read Full License

Version of Record: A version of this preprint was published at Environmental Science and Pollution Research on November 6th, 2021. See the published version at https://doi.org/10.1007/s11356-02117312-w. 


\section{Abstract}

The effects of magnetic field treatments on the two determining factors of phytoremediation, growth status and element uptake capacity, of Sedum alfredii have been thoroughly studied; however, minimal studies have been performed to determine the influence of the Cd hyperaccumulator Sedum alfredii, grown from magnetically treated seeds, on the dissolved organic matter (DOM) characteristics in its rhizosphere. A series of pot experiments were conducted to evaluate the variations in the DOM concentration and fractionations in the rhizosphere of $S$. alfredii treated with external magnetic fields. Compared with the untreated seeds, $S$. alfredii grown from magnetically treated seeds excreted more DOM in its rhizosphere. Additionally, the hydrophilic DOM fractionation proportion, which presented a greater capacity to mobilize $\mathrm{Cd}$ in the soil, increased from $42.7 \%$ in the control sample to $47.2 \%$ in the $150 \mathrm{mT}$ magnetically treated $S$. alfredii sample. The water-soluble and exchangeable forms of $\mathrm{Cd}$ (extracted using deionized water and $\mathrm{NH}_{4} \mathrm{NO}_{3}$, respectively) in the rhizosphere of the magnetically treated S. alfredii were significantly lower than those of the control sample. Furthermore, the Cd extraction capacity of DOM from the rhizosphere of the magnetically treated $S$. alfredii was greater than that of the control sample, thereby increasing the Cd uptake ability of the magnetically treated species. These results suggest that the secretion of large amounts of DOM, especially acid and hydrophilic fractionations, is an essential mechanism of magnetically treated $S$. alfredii to mobilize $\mathrm{Cd}$ in the soil.

\section{Introduction}

Cd, a well-known trace inorganic contaminant with high bioavailability and a long biological half-life, has detrimental effects on human health (Xiao et al., 2017). Cd-polluted soil decontamination using conventional technologies such as soil washing, excavation, in-situ solidification, and electrokinetic remediation is expensive and could damage the physical structure and ecological system of the soil (Komínková et al., 2018).

Phytoextraction, the application of hyperaccumulators to remove pollutants from contaminated sites via plant uptake and migration to harvestable tissues, is an economical, ecologically friendly alternative to the traditional physical and chemical decontamination methods of contaminated sites. Various hyperaccumulator types, including Noccaea caerulescens for Cd and Zn (Escarre et al., 2000), Pteris vittata for As (Gonzaga et al., 2009), Arabis paniculate for Pb (Tang et al., 2009), and Phytolacca acinosa for Mn (Xue et al., 2004) have been identified and studied to evaluate the mobilization, extraction, transportation, hyperaccumulation, and detoxification mechanisms of contaminants in these plants. The major constraint restricting the widespread utilization of hyperaccumulators for soil remediation is the low biomass generation abilities of these plants (Li et al., 2018).

Improving the dry weight and metal uptake efficiency of hyperaccumulators is critical for phytoextraction in metal-polluted fields; therefore, a thorough understanding of hyperaccumulator mechanisms that activate and accumulate metals is necessary. Previous studies have suggested that the application of an appropriate external magnetic field can enhance the phytoremediation efficiencies of Eucalyptus globulus 
(Luo et al., 2019a), N. caerulescens (Luo et al., 2019b), and Festuca arundinacea (Luo et al., 2020). For instance, an appropriate magnetic field can improve biomass yield and metal uptake efficiency by activating membrane transporters in plant tissues, providing energy for $\mathrm{Mg}^{2+}$ to biosynthesize chlorophyll, and enhancing the antioxidant enzyme activities in plants to scavenge excessive free radicals as a result of balancing the endogenous biological magnetic field.

Root-soil interactions can also modulate the metal activity in the rhizosphere and consequent alterations in the metal uptake abilities of plants. Many factors, including $\mathrm{pH}$, cation exchange capacity, alkalinity, organic matter, microbial activity, and moisture content, can influence metal activity in the rhizosphere. The variation in $\mathrm{pH}$ in hyperaccumulator-growing soils has been thoroughly studied; however, inconsistent results have been reported. For example, Loosemore et al. (2004) found that the pH in the Nicotiana tabacum rhizosphere significantly decreased after growth occurred; however, McGrath et al. (1997) found that the $\mathrm{pH}$ in the $N$. caerulescens rhizosphere did not change, and Kim et al. (2010) reported that rhizosphere $\mathrm{pH}$ increased by 1.3 after $B$. juncea cultivation. These inconsistent results suggest that $\mathrm{pH}$ reduction in the rhizosphere is not the only metal activating mechanism in the rhizosphere by accumulators.

Previous studies suggest that dissolved organic matter (DOM) controls metal fractionation and bioavailability rather than $\mathrm{pH}$ when the latter is higher than 6.5; therefore, DOM features in the rhizosphere should be considered during the phytoremediation process (Christensen and Christensen, 2000). DOM that can pass through a $0.45-\mu \mathrm{m}$ filter has an affinity for bonding with metals, thus increasing metal bioavailability in the rhizosphere (Beiyuan et al., 2018; Bradney et al., 2019; El-Naggar et al., 2018). Kim et al. (2010) reported that plants could spontaneously adjust their rhizosphere to improve the uptake of beneficial elements by various mechanisms, such as acidification, lowering of oxidation-reduction potential, and organic matter excretion. Furthermore, hyperaccumulators secrete more DOM into their rhizosphere when subjected to high-metal environments, resulting in a decreased extraction rate of the corresponding metal hyperaccumulation by these plants (Guilpain et al., 2018; Tao et al., 2020). Based on previous studies on the major DOM characteristics and its impact on metal bioavailability in the rhizosphere, it has been determined that $\mathrm{DOM}$ can significantly reduce $\mathrm{Cu}, \mathrm{Pb}, \mathrm{Ni}$, and $\mathrm{Cd}$ adsorption by soil particles, which increases the solubilities of these metals (Li et al., 2013c). However, the effects of magnetically treated plants on DOM fractionation and metal bioavailability are not thoroughly understood; therefore, further evaluation is necessary to determine their effects on the rhizosphere of these plants during the phytoextraction process.

S. alfredii, a Crassulacean acid metabolism species found in South China, is a candidate for phytoextraction in Cd-polluted fields owing to its physiological features (Li et al., 2013b). Previous studies reported that an appropriate external magnetic field stimulated the growth rates of hyperaccumulators and high-biomass producing plants and improved their metal uptake capacities (Luo et al., 2019a, 2019b, 2020). Therefore, magnetic field application could alter the DOM characteristics in the rhizosphere of $S$. alfredii. The primary goals of this study were to evaluate the effects of magnetic field treatment on DOM concentrations and fractionations in the rhizosphere of $S$. alfredii, investigate the Cd extraction capacity 
of DOM from the rhizosphere of magnetically treated $S$. alfredii, and verify the feasibility of using magnetic fields to improve the phytoremediation efficiency of $S$. alfredii.

\section{Materials And Methods}

\subsection{Plant and soil materials}

S. alfredii seeds were gathered from a lead-zinc mine in Shangfang Town, Quzhou City, China, and separated into four groups. Three groups were placed in non-magnetic containers and treated with a 50, 100, and $150 \mathrm{mT}$ intensity static magnetic field for 20 min each day for one week, and the fourth group was exposed to a geomagnetic field and used as the control. Each treatment had five replicates. A field generator was used to produce the static magnetic field, and intensity stability was monitored using a Gauss magnetometer. After pre-sowing treatment, all plants were cultivated for 14 days under greenhouse conditions in a nutrient solution (Lu et al., 2008).

The heavily contaminated soils used in this experiment were obtained from the top layer $(20 \mathrm{~cm})$ of a well-known electronic waste recycling center, Guiyu, located in south China, in which the soils have been heavily polluted owing to electronic waste dismantling activities using primitive recycling methods (Jiang et al., 2019). After air-drying, the soils were ground and sieved using a 2-mm nylon mesh. Four rounds of the wetting and drying processes were performed to equilibrate the soil, and then the mixed soil was divided into $6 \mathrm{~kg}$ aliquots and stored in PVC pots for S. alfredii transplantation. The Cd concentrations in the homogenized soil were $3.83 \pm 0.46 \mathrm{mg} \mathrm{kg}^{-1}$.

Four pre-cultured seedlings were transplanted into each pot. During the growth process, soil moisture was maintained at $70 \%$ field capacity using deionized water and measuring the weights every day. Ninety days after the start of the experiment, all plants were carefully harvested, and rhizosphere soils from each pot were obtained by shaking the roots (Luster et al., 2009). The soil pH was measured before and after transplantation using a pH meter in a 1:2.5 soil-water suspension.

The harvested plant tissues were washed with tap water to remove foreign materials and then soaked in a $10 \mathrm{mM}$ EDTA-Na ${ }_{2}$ solution to eliminate adsorbed ions. The cleaned tissues were dried in a $70^{\circ} \mathrm{C}$ oven until a constant weight was achieved.

\subsection{DOM extraction and fractionation}

The DOM in the rhizosphere of $S$. alfredii was extracted following the procedures suggested by Jones and Willett (2006) with minor modifications, wherein $2.5 \mathrm{~g}$ of the rhizosphere soil was mixed with $25 \mathrm{~mL}$ of distilled water and shaken at $200 \mathrm{rpm}$ for $120 \mathrm{~min}$. The extracts were centrifuged at 10,000 $\times \mathrm{g}$ for 20 min, and the recovered supernatant was sieved using $0.45-\mu \mathrm{m}$ filters. A total organic carbon analyzer (TOC-5000, Shimadzu, Japan) was used to measure the dissolved organic carbon in the filtrate. Leenheer and Croue (2003) developed a dissolved organic carbon fractionation method that classified dissolved organics into six fractionations, including hydrophilic acid, hydrophilic base, hydrophilic neutral, 
hydrophobic acid, hydrophobic base, and hydrophobic neutral based on their polarity, alkaline-acidic properties, and specific compound characteristics. The DOM fractionation was performed according to the method suggested by Leenheer and Croue (2003), and the six DOM fractions were measured using the total organic carbon analyzer (TOC-5000, Shimadzu, Japan).

\subsection{Cd extraction capacity of DOM}

Cations in the extracted DOM were removed using an Amberlite cation exchange $\mathrm{H}$ resin (Sigma-Aldrich, USA). After dilution to $100 \mathrm{mg} \mathrm{L}^{-1}$ with deionized water, $20 \mathrm{~mL}$ of the solution was mixed with $2 \mathrm{~g}$ of soil in a centrifugal tube and centrifuged at $8000 \times \mathrm{g}$ for $30 \mathrm{~min}$. After being sieved through a $0.45-\mu \mathrm{m}$ membrane, the $\mathrm{Cd}$ concentration in the recovered supernatant was measured using an inductively coupled plasma mass spectrometer (ICP-MS) (Agilent 7700, USA). The soil samples ( $2 \mathrm{~g}$ ) were mixed with deionized water and prepared using the same procedure as the control.

\subsection{Cd analysis}

The dried plant and rhizosphere soil samples were ground and sieved using a 74- $\mu$ m nylon mesh. The plant samples were digested through the aqua regia dissolution method (Ok et al., 2011), wherein the prepared plant samples were digested in a solution of $\mathrm{HNO}_{3}$ and $\mathrm{HCl}(1: 3$ ratio) and heated for 100 min at $130^{\circ} \mathrm{C}$. After cooling, the digestion was filtered through a $0.45-\mu \mathrm{m}$ membrane, and the $\mathrm{Cd}$ concentration in the recovered filtrate was analyzed via ICP-MS (Agilent 7700, USA).

The water-soluble and exchangeable fractions of $\mathrm{Cd}$ in the rhizosphere were determined according to the methodology described in a previous study (He et al., 2020), wherein $1.2 \mathrm{~g}$ of dried soil was shaken with $25 \mathrm{~mL} \mathrm{CaCl}_{2}\left(10 \mathrm{mmol} \mathrm{L}^{-1}\right)$ in a centrifugal tube at $200 \mathrm{rpm}$ for $30 \mathrm{~min}$ and then centrifuged at $4000 \times \mathrm{g}$ for $15 \mathrm{~min}$. After filtration through a $0.45-\mu \mathrm{m}$ filter, the supernatant was collected and the water-soluble $\mathrm{Cd}$ was measured using the ICP-MS (Agilent 7700, USA).

The residue recovered from the water-soluble extraction was shaken with $25 \mathrm{~mL}$ of $\mathrm{NH}_{4} \mathrm{NO}_{3}\left(1 \mathrm{~mol} \mathrm{~L}^{-1}\right)$ in a centrifugal tube at $200 \mathrm{rpm}$ for $30 \mathrm{~min}$. During shaking, the $\mathrm{pH}$ of the mixture was maintained at 7.0 (He et al., 2020). The centrifugation and analysis procedures in the exchangeable $\mathrm{Cd}$ fraction were identical to those used for the water-soluble fraction.

Carbonate, Fe-Mn oxide, organic matter, and the residual fractions of $\mathrm{Cd}$ in the remaining sedimentation reclaimed from the exchangeable extraction were extracted using $1 \mathrm{M} \mathrm{NaOAc}$, a mixture of $0.04 \mathrm{M}$ $\mathrm{NH}_{2} . \mathrm{OH} . \mathrm{HCl}$ and $25 \% \mathrm{HOAc}$, a mixture of $0.02 \mathrm{M} \mathrm{HNO}_{3}$ and $30 \% \mathrm{H}_{2} \mathrm{O}_{2}$, and aqua regia in sequence, according to $\mathrm{Li}$ and Thornton (2001). The sum of these six chemical fractions represented the total $\mathrm{Cd}$ concentration in the rhizosphere.

Quality control was performed by analyzing two reference materials, GBW07410 (soil) and GBW10012 (plant), which were obtained from the China Standard Materials Research Center (Beijing, China).

\subsection{Statistical analysis}


The data are represented as the average of the five replicates used in this experiment. The magnetic field treatment effects on the dry weight of $S$. alfredii, DOM concentration and fractionations in the rhizosphere, mobile $\mathrm{Cd}$ in the soil, and $\mathrm{Cd}$ extraction ability of DOM were tested via one-way analysis of variance. Means of significant difference $(p<0.05)$ were evaluated by Fisher's protected least significant difference test, and SPSS 15.0 software was used to conduct the statistical analyses in this study.

\section{Results And Discussion \\ 3.1 Soil pH}

A significant $\mathrm{pH}$ variation among the treatments was not observed during this study. Compared with the initial soil $\mathrm{pH}(6.1 \pm 0.2)$ at transplantation, the magnetically treated and untreated $S$. alfredii reduced the $\mathrm{pH}$ by 0.2 and 0.1 , respectively, in its rhizosphere during the 90 -day experiment. These results indicate that the soil used can buffer the plant-induced $\mathrm{pH}$ variation, and the $\mathrm{pH}$ changes in the $S$. alfredii rhizosphere are not responsible for $\mathrm{Cd}$ mobilization in this experiment.

Soil pH significantly influences the metal activity in the substrate, which is enhanced by reducing the $\mathrm{pH}$ value (Hu et al., 2018; Römkens et al., 2002; Wang et al., 2020). The pH variation in the rhizosphere soil has been reported for other plants. For instance, $N$. tabacum reduces the $\mathrm{pH}$ in the rhizosphere (Loosemore et al., 2004), B. juncea increases the soil pH significantly (Kim et al., 2010), and $N$. caerulescens has no effect on the $\mathrm{pH}$ in the rhizosphere (McGrath et al., 1997). The pH variation in the soil is a complex process that is dependent on soil properties, plant types, and weather conditions. Generally, $\mathrm{Cd}$ is present as an oxyanion in soil, and its uptake by $S$. alfredii could enhance the $\mathrm{pH}$ in the rhizosphere because the plant releases $\mathrm{OH}^{-}$in the soil to maintain the charge balance after extracting $\mathrm{Cd}$. Decreased soil pH was caused by increased root secretions, including rhamnolipids, surfactin, and humic and fulvic acids (Davin et al., 2018). The combination of these two processes could determine the final soil $\mathrm{pH}$ during phytoremediation.

\subsection{DOM concentration and fractionation}

The final DOM concentrations in the rhizospheres of the 50,100, and $150 \mathrm{mT}$ treated $S$. alfredii were $156.9,192.5$, and $198.3 \mathrm{mg} \mathrm{kg}^{-1}$, respectively, which are higher than the initial concentration of the experiment $\left(129.3 \mathrm{mg} \mathrm{kg}^{-1}\right)$. Compared with the control that was exposed to a geomagnetic field, the 100 and $150 \mathrm{mT}$ treatments significantly increased the DOM concentrations in the rhizosphere of $S$. alfredii (Fig. 1), while the $50 \mathrm{mT}$ treatment had a slightly lower value $(p>0.05)$. The 100 and $150 \mathrm{mT}$ treated samples showed $17.6 \%$ and $21.1 \%$ increases in the DOM concentrations in the soil, respectively, relative to the control; however, no significant DOM concentration differences were observed between the 100 and $150 \mathrm{mT}$ treatments (Fig. 1).

The different fraction distributions in the soil of the various treatments are presented in Fig. 2. The DOM fractions in the $S$. alfredii soil exhibited different distribution trends among various treatments, and the hydrophobic fraction concentrations (hydrophobic acid, base, and neutral) did not significantly vary 
among the treatments during phytoremediation. In contrast, the hydrophilic fraction concentrations (hydrophilic acid, base, and neutral) were significantly enhanced when treated by 100 and $150 \mathrm{mT}$ than those treated with the geomagnetic field and $50 \mathrm{mT}$. Generally, the control had higher hydrophobic fraction concentrations than the other treatments, while the $150 \mathrm{mT}$ treatment showed higher hydrophilic fraction concentrations than the other treatments. The acid fraction concentrations (hydrophilic and hydrophobic acid) were significantly higher in the 100 and $150 \mathrm{mT}$ treatments than in the control and 50 $\mathrm{mT}$ treatments.

Furthermore, the acid fraction was the predominant DOM component in all the soil treatments, accounting for $77.8 \%, 76.5 \%, 77.1 \%$, and $74.9 \%$ of the DOM in the soil of the control, 50, 100, and 150 $\mathrm{mT}$ treatments, respectively. Meanwhile, the hydrophobic fraction proportion decreased from $57.3 \%$ to $43.0 \%$, and the hydrophilic fraction proportion increased from $42.7 \%$ to $57.2 \%$ in the control and $150 \mathrm{mT}$ treatment, respectively.

During the phytoremediation process, root secretion is one of the most significant DOM sources (Martin et al., 2017); therefore, the elevated DOM concentrations in the soils at the end of the experiment might be induced by the presence of $S$. alfredii. Although the effects of external magnetic fields on root secretion have not been determined, many studies suggest that magnetic fields regulate plant metabolism and growth rate on the cellular, subcellular, and molecular levels (Ćirković et al., 2017; Shokrollahi et al., 2018; Teixeira da Silva and Dobránszki, 2016). Therefore, the increased DOM concentration in the rhizosphere of magnetically treated $S$. alfredii could be partially induced by the stimulation of the applied magnetic fields.

DOM contains many functional components, including sulfhydryl, amino, and phosphoryl groups, which have a strong affinity to metals and increase the metal bioavailability in soil (Borggaard et al., 2019; Zhou et al., 2019). The chemical activity of hydrophilic acids is greater than that of hydrophobic acids because the former have more functional groups that can activate the metals in soil (Huang et al., 2019).

Therefore, the chemical components of DOM in the rhizospheres of the 100 and $150 \mathrm{mT}$ treated $S$. alfredii are more conducive to increasing $\mathrm{Cd}$ mobility. The mechanisms in which magnetic fields regulate root exudation regarding the physiological characteristics of plants require further investigation.

\subsection{Chemical fractions of $\mathrm{Cd}$ in the rhizosphere}

S. alfredii growth did not change the total Cd concentration in the soil compared to the initial state; however, it increased the variable coefficient of the metal (Fig. 3), which concurs with the findings of a previous study, suggesting that plant growth can heterogenize the soil over time (He et al., 2020).

The chemical fractions of $\mathrm{Cd}$ in the soil were analyzed at the beginning and end of the experiment. The initial water-soluble and exchangeable Cd concentrations in the soil decreased significantly after the cultivation of $S$. alfredii under all treatments, and the reduction in the rhizosphere increased with increasing magnetic intensity. Compared with the control, the $50 \mathrm{mT}$ treatment did not significantly change the water-soluble $\mathrm{Cd}$ concentration, but it significantly decreased the exchangeable fraction 
concentration (Fig. 3). However, the 100 and $150 \mathrm{mT}$ treatments decreased the water-soluble and exchangeable $\mathrm{Cd}$ concentrations, and their lowest concentrations were observed in the $\mathrm{S}$. alfredii rhizosphere exposed to $150 \mathrm{mT}$. Li et al. (2013a) compared the water-soluble Cd concentration variations in soils after the growth of hyperaccumulating and non-hyperaccumulating ecotypes of $S$. alfredii. They found that the hyperaccumulating ecotype of $S$. alfredii decreased the water-soluble $C d$ in slightly contaminated soil, which agrees with the results of this study. In contrast, the non-hyperaccumulating ecotype of $S$. alfredii increased the water-soluble $\mathrm{Cd}$ in the rhizosphere because $S$. alfredii activates $\mathrm{Cd}$ in the soil through increased root excretions, and Cd solubilization is faster than the $\mathrm{Cd}$ uptake by the plant.

The water-soluble and exchangeable Cd concentrations in the soils decreased significantly after the $S$. alfredii growth with or without magnetic field treatment. However, the chemical fraction reductions in the rhizosphere were less than $1 \%$ of the extraction amount in the $S$. alfredii, indicating that more than $99 \%$ of the $\mathrm{Cd}$ uptake migrated from other fractions. Soils can spontaneously maintain a dynamic balance of a specific element during plant growth via a pair of opposite processes, i.e., mobilizing the element in soil and its extraction by plants. This study shows that the effective $C d$ extraction root system of $S$. alfredii can eliminate water-soluble and exchangeable $\mathrm{Cd}$ faster than the rate $\mathrm{Cd}$ is supplemented from other chemical fractions, and $S$. alfredii, particularly the magnetically treated species, can mobilize $C d$ that is not initially bioavailable. The mobilizing ability of $S$. alfredii increased with increasing magnetic field intensity.

Increased DOM in the rhizosphere of the species can regulate the $\mathrm{Cd}$ mobilization process. As shown in Fig. 3, the proportion of organic matter Cd increased significantly from $11.0 \%$ in the control to $25.7 \%$ and $25.9 \%$ in the 100 and $150 \mathrm{mT}$ treatments, respectively, while no significant changes in the carbonate, $\mathrm{Fe}-$ Mn oxide, and residual fraction proportions were observed. This finding is consistent with the results suggested by Krishnamurti et al. (2004) who suggested that Cd-DOM complexes can be taken up intact by Chlorococcum sp. and result in increased Cd toxicity. Generally, soil pH and DOM concentration are the two dominant factors controlling bioavailability and chemical activity in soil (Christensen and Christensen, 2000). In this study, soil pH did not vary after plant growth; therefore, the variation in the chemical fraction of $\mathrm{Cd}$ in the soil is mainly driven by the increased DOM in the rhizosphere.

\subsection{Cd extraction capacity of DOM from the rhizosphere}

The DOM in the magnetically treated soils of $S$. alfredii significantly enhanced the Cd solubility in the soils relative to deionized water (Fig. 4). For example, the Cd concentration extracted using $100 \mathrm{mg} \mathrm{L}^{-1}$ DOM from the control and the 50,100, and $150 \mathrm{mT}$ treatments were $48.3 \%, 58.6 \%, 137.9 \%$, and $151.7 \%$ higher, respectively, than that extracted using deionized water, indicating that the $\mathrm{Cd}$ extraction capacity of DOM improved with increasing magnetic field intensity.

Borggaard et al. (2019) reported that increased DOM concentration improved the metal solubility in the soil and attributed the metal extractability to hydrophilic fractions. Chen et al. (2018) studied the influence of DOM on Zn extractability in calcareous soil and suggested that the addition of maize straw resulted in increased amounts of applied Zn recovered by the DTPA-extractable fraction, which is 
attributed to the increased DOM concentration and consequently, increased formation of Zn-fulvic acid complexes. Additionally, the DOM from the soils of the 100 and $150 \mathrm{mT}$ treated $S$. alfredii had a greater ability to mobilize $\mathrm{Cd}$ in the rhizosphere compared with the control and $50 \mathrm{mT}$ treatment. For instance, the Cd concentration extracted by the DOM in the $150 \mathrm{mT}$ treatment was $0.73 \mathrm{mg} \mathrm{L}^{-1}$, which was 0.70 and 0.59 times greater than that of the control and $50 \mathrm{mT}$ treatments, respectively. This indicates that the DOM fractions under the different magnetic field treatments varied and potentially influenced $\mathrm{Cd}$ mobilization. Furthermore, the magnetically treated $S$. alfredii had a greater capacity to generate chelates with Cd compared with the control.

\subsection{Phytoextraction efficiency}

The average soil Cd concentration difference before and after transplantation could not be used to estimate the phytoextraction efficiency of $S$. alfredii because the duration of the experiment was not long enough for the $S$. alfredii to change the total Cd concentration in its rhizosphere. Therefore, the Cd uptake in the harvested tissues was calculated to evaluate the phytoremediation effect of $S$. alfredii.

The Cd uptake of $S$. alfredii was defined as the product of the plant's dry weight (belowground and aerial plant parts) and Cd concentration. As shown in Table 1, the $150 \mathrm{mT}$ treated S. alfredii had the largest dry weight, and that of the 100 and $50 \mathrm{mT}$ treatments and the control were successively lower. Except for the $50 \mathrm{mT}$ treatment, magnetic field treatments significantly improved the dry weight. Similarly, Cd concentrations in the belowground and aerial plant parts increased with increasing magnetic field intensity (Table 1), consistent with the DOM concentration and fraction variation trends in the $S$. alfredii rhizosphere.

Table 1

Dry weight, Cd concentrations, and Cd decontamination capacity of $S$. alfredii in different treatments

\begin{tabular}{|c|c|c|c|c|c|}
\hline & \multicolumn{2}{|c|}{ Dry weight (g) } & \multicolumn{2}{|l|}{ Cd content } & \multirow{2}{*}{$\begin{array}{l}\text { Cd accumulation } \\
\left(\mathrm{mg} \mathrm{pot}^{-1}\right)\end{array}$} \\
\hline & Roots & Shoots & Roots & Shoots & \\
\hline control & $0.73 \pm 0.12$ & $8.21 \pm 1.25$ & $22.3 \pm 2.9$ & $71.2 \pm 5.6$ & 2.4 \\
\hline $50 \mathrm{mT}$ & $0.69 \pm 0.08$ & $9.22 \pm 1.03$ & $25.6 \pm 2.2$ & $66.5 \pm 6.1$ & 2.5 \\
\hline $100 \mathrm{mT}$ & $1.02 \pm 0.09$ & $10.63 \pm 1.52$ & $29.7 \pm 3.1$ & $90.5 \pm 9.1$ & 4 \\
\hline $150 \mathrm{mT}$ & $1.12 \pm 0.15$ & $12.39 \pm 2.56$ & $38.1 \pm 2.6$ & $95.7 \pm 7.1$ & 4.9 \\
\hline
\end{tabular}

Based on the dry weight and Cd content, 2.4, 2.5, 4.0, and $4.9 \mathrm{mg}$ of Cd were extracted from the control, 50,100 , and $150 \mathrm{mT}$ treatment pots. The excess $\mathrm{Cd}$ in each pot that required removal was calculated as the product of the difference between the initial soil Cd concentration $\left(3.83 \mathrm{mg} \mathrm{kg}^{-1}\right)$ and its safe threshold $\left(0.30 \mathrm{mg} \mathrm{kg}^{-1}\right)$ and the soil mass $(6 \mathrm{~kg})$. The required number of planting cycles to clean the soil was determined by the excess Cd divided by the Cd uptake capacity of $S$. alfredii, therefore, 9, 9, 6, 
and 5 planting cycles are required for $S$. alfredii to decontaminate the soil in the control, 50, 100, and 150 $\mathrm{mT}$ treatments, respectively.

A previous study concluded that an appropriate magnetic field improves the plant dry weight by increasing antioxidant enzyme activity that scavenges oxyradicals resulting from stresses, balancing the internal magnetic field in plants, and increasing cytomembrane permeability to enhance nutrient pass through (Luo et al., 2020). The study focused on the plant improvement effects of magnetic fields rather than effects on the rhizosphere. Previous studies have shown that many plants can modulate the chemical properties of their rhizosphere to improve pollutant extraction via various pathways, including acidification, stimulating microbial proliferation, and DOM excretion (Cao et al., 2018; Gattullo et al., 2015). This study found that the increased Cd uptake capacity of magnetically treated $S$. alfredii was related to increased DOM concentrations and its acid and hydrophilic fractions. Furthermore, higher Cd extractability was observed for DOM under magnetic field treatments, particularly when exposed to 150 $\mathrm{mT}$, indicating that DOM from magnetically treated soils exhibits a greater capacity to mobilize Cd in the soil by generating a complex.

The Cd extraction capacity of magnetically treated $S$. alfredii, particularly at $150 \mathrm{mT}$, was much greater than that of the control and decreased the required remediation time by half. This study demonstrated that applying an appropriate magnetic field is an effective method to enhance the phytoextraction efficiency of $S$. alfredii based on the variation in DOM concentrations and its fractions in the soil.

\section{Conclusions}

This study determined that magnetic field treatment, particularly a $150 \mathrm{mT}$ treatment, improves the phytoextraction of $S$. alfredii by increasing its dry weight and Cd uptake capacity. Compared to the control, the DOM concentrations and acid fractions were significantly higher in the 100 and $150 \mathrm{mT}$ treatments. Additionally, the hydrophilic fraction proportions significantly influence metal mobilization in the soil, which increases with increasing magnetic intensity. Compared with the initial state, water-soluble and exchangeable $\mathrm{Cd}$ in the rhizosphere decreased significantly after the $S$. alfredii growth, and the decreases were significantly higher in the magnetically treated plants than in the control. The Cd extraction capacity of DOM from the rhizosphere of magnetically treated $S$. alfredii was significantly higher than that of the control, thus increasing the $\mathrm{Cd}$ concentrations in the plant tissues. This study reveals that the primary mechanism to increase Cd extraction in $S$. alfredii is the DOM in magnetically treated $S$. alfredii, which increases the $\mathrm{Cd}$ mobilization capacity in the rhizosphere by generating DOM-Cd (organic matter $\mathrm{Cd}$ fraction) and consequently increases the phytoextraction efficiency of $S$. alfredii in Cdpolluted soil.

\section{Declarations}

Corresponding author's email address: gchero1216@hotmail.com 
Ethical Approval: Not applicable. This work did not describe experiments with animals, human subjects, or human tissue samples.

Consent to Participate: Not applicable. This work did not describe experiments with animals, human subjects, or human tissue samples.

Consent to Publish: The manuscript entitled, "Effects of magnetically treated Sedum alfredii seeds on the dissolved organic matter characteristics of Cd-contaminated soil during phytoextraction" is prepared in accordance with the Guide for authors available on the journal's website and it has not been published elsewhere in part or in its entirety. All authors attest to the validity of its contents, and agree to its submission in Environmental Science and Pollution Research.

Authors Contributions: Conceptualization, Youjun Tang, Jie Luo; Data curation, Shuaizhi Ji, Jiawei Wang; Methodology, Jie Luo, Dan Chen; Funding acquisition, Jie Luo; Writing - original draft, Youjun Tang, Shuaizhi Ji, Jie Luo; Writing - review \& editing, Min Cao, Dan Chen. All authors read and approved the final manuscript.

Funding: The authors thank the National Natural Science Foundation of China (Project No. 21876014) for financial support to carry out this study.

Competing Interests: None of the authors have any competing interests.

Availability of data and materials: The datasets used or analyzed during the current study are available from the corresponding author on reasonable request. All data generated or analyzed during this study are included in this published article.

\section{References}

1. Beiyuan J, Lau AYT, Tsang DCW, Zhang W, Kao CM, Baek K, Ok YS, Li XD (2018) Chelant-enhanced washing of CCA-contaminated soil: Coupled with selective dissolution or soil stabilization. Sci Total Environ 612:1463-1472

2. Borggaard OK, Holm PE, Strobel BW (2019) Geoderma Potential of dissolved organic matter (DOM) to extract $\mathrm{As}, \mathrm{Cd}, \mathrm{Co}, \mathrm{Cr}, \mathrm{Cu}, \mathrm{Ni}, \mathrm{Pb}$ and $\mathrm{Zn}$ from polluted soils : A review. Geoderma 343:235-246

3. Bradney L, Wijesekara H, Palansooriya KN, Obadamudalige N, Bolan NS, Ok YS, Rinklebe J, Kim KH, Kirkham MB (2019) Particulate plastics as a vector for toxic trace-element uptake by aquatic and terrestrial organisms and human health risk. Environ Int 131:1-18

4. Cao B, Jiang Z, Li J, Zhang X, Hu Y, Chen J, Zhang Y (2018) Different dissolved organic matter (DOM) characteristics lead to diverse atrazine adsorption traits on the non-rhizosphere and rhizosphere soil of Pennisetum americanum (L.) K. Schum Chemosphere 209:608-616

5. Chen Y, Shi J, Tian X, Jia Z, Wang S, Chen J, Zhu W (2018) Impact of dissolved organic matter on Zn extractability and transfer in calcareous soil with maize straw amendment. J Soils Sediments 
19:774-784

6. Christensen JB, Christensen TH (2000) The effect of pH on the complexation of Cd, Ni and $\mathrm{Zn}$ by dissolved organic carbon from leachate-polluted groundwater. Water Res 34:3743-3754

7. Ćirković S, Bačić J, Paunović N, Popović TB, Trbovich AM, Romčević N, Ristić-Djurović JL (2017) Influence of $340 \mathrm{mT}$ static magnetic field on germination potential and mid-infrared spectrum of wheat. Bioelectromagnetics 38:533-540

8. Davin M, Starren A, Deleu M, Lognay G, Colinet G, Fauconnier ML (2018) Could saponins be used to enhance bioremediation of polycyclic aromatic hydrocarbons in aged-contaminated soils? Chemosphere 194:414-421

9. El-Naggar A, Shaheen SM, Ok YS, Rinklebe J (2018) Biochar affects the dissolved and colloidal concentrations of $\mathrm{Cd}, \mathrm{Cu}, \mathrm{Ni}$, and $\mathrm{Zn}$ and their phytoavailability and potential mobility in a mining soil under dynamic redox-conditions. Sci Total Environ 624:1059-1071

10. Escarre J, Lefebvre C, Gruber W, Leblanc M (2000) Zinc and cadmium hyperaccumulation by from metalliferous Thiaspi caerulescens and nonmetalliferous sites in the Mediterranean area: implications for phytoremediation. New Phytol 145:429-437

11. Gattullo CE, Kiersch K, Eckhardt KU, Baum C, Leinweber P, Loffredo E (2015) Decontamination Activity of Ryegrass Exudates Towards Bisphenol A in the Absence and Presence of Dissolved Natural Organic Matter. Int J Phytorem 17:1-8

12. Gonzaga MIS, Ma LQ, Santos JAG, Matias MIS (2009) Rhizosphere characteristics of two arsenic hyperaccumulating Pteris ferns. Sci Total Environ 407:4711-4716

13. Guilpain M, Laubie B, Zhang X, Morel JL, Simonnot MO (2018) Speciation of nickel extracted from hyperaccumulator plants by water leaching. Hydrometallurgy 180:192-200

14. He W, Long A, Zhang C, Cao M, Luo J (2020) Mass balance of metals during the phytoremediation process using Noccaea caerulescens: a pot study. Environ Sci Pollut Res. DOI:10.1007/s11356-02011216-X

15. Hu Y, Huang Y, Su J, Gao Z, Li S, Nan Z (2018) Temporal changes of metal bioavailability and extracellular enzyme activities in relation to afforestation of highly contaminated calcareous soil. Sci Total Environ 622-623:1056-1066

16. Huang B, Liu G, Wang P, Zhao X, Xu H (2019) Effect of Nitric Acid Modification on Characteristics and Adsorption Properties of Lignite. Processes 7:1-16

17. Jiang S, Luo J, Ye Y, Yang G, Pi W, He W (2019) Using Pb Isotope to Quantify the Effect of Various Sources on Multi-Metal Polluted soil in Guiyu. Bull Environ Contam Toxicol 102:413-418

18. Jones DL, Willett VB (2006) Experimental evaluation of methods to quantify dissolved organic nitrogen (DON) and dissolved organic carbon (DOC) in soil. Soil Biol Biochem 38:991-999

19. Kim KR, Owens G, Naidu R, Kwon S, Ik (2010) Influence of plant roots on rhizosphere soil solution composition of long-term contaminated soils. Geoderma 155:86-92 
20. Komínková D, Fabbricino M, Gurung B, Race M, Tritto C, Ponzo A (2018) Sequential application of soil washing and phytoremediation in the land of fires. J Environ Manage 206:1081-1089

21. Krishnamurti GSR, Megharaj M, Naidu R (2004) Bioavailability of cadmium-organic complexes to soil alga - An exception to the free ion model. J Agric Food Chem 52:3894-3899

22. Leenheer JA, Croue JP (2003) Characterizing dissolved aquatic organic matter. Environ Sci Technol $1: 19-26$

23. Li JT, Gurajala HK, Wu LH, Van Der Ent A, Qiu RL, Baker AJM, Tang YT, Yang XE, Shu WS (2018) Hyperaccumulator Plants from China: A Synthesis of the Current State of Knowledge. Environ Sci Technol 52:11980-11994

24. Li T, Liang C, Han X, Yang X (2013a) Mobilization of cadmium by dissolved organic matter in the rhizosphere of hyperaccumulator Sedum alfredii. Chemosphere 91:970-976

25. Li T, Tao Q, Han X, Yang X (2013b) Effects of elevated CO2 on rhizosphere characteristics of Cd/Zn hyperaccumulator Sedum alfredii. Sci Total Environ 454-455:510-516

26. Li T, Tao Q, Liang C, Shohag MJI, Yang X, Sparks DL (2013c) Complexation with dissolved organic matter and mobility control of heavy metals in the rhizosphere of hyperaccumulator Sedum alfredii. Environ Pollut 182:248-255

27. Li X, Thornton I (2001) Chemical partitioning of trace and major elements in soils contaminated bymining and smelting activities. Appl Geochem 16:1693-1706

28. Loosemore N, Straczek A, Hinsinger P, Jaillard B (2004) Zinc mobilisation from a contaminated soil by three genotypes of tobacco as affected by soil and rhizosphere pH. Plant Soil 260:19-32

29. Lu LL, Tian SK, Yang XE, Wang XC, Brown P, Li TQ, He ZL (2008) Enhanced root-to-shoot translocation of cadmium in the hyperaccumulating ecotype of Sedum alfredii. J Exp Bot 59:32033213

30. Luo J, He W, Qi S, Wu J, Gu XS (2020) A novel phytoremediation method assisted by magnetized water to decontaminate soil $\mathrm{Cd}$ based on harvesting senescent and dead leaves of Festuca arundinacea. J Hazard Mater 383:1-6

31. Luo J, He W, Xing X, Wu J, Gu XWS (2019a) The phytoremediation efficiency of Eucalyptus globulus treated by static magnetic fields before sowing. Chemosphere 226:891-897

32. Luo J, He W, Yang D, Wu J, Sophie. Gu XW (2019b) Magnetic field enhance decontamination efficiency of Noccaea caerulescens and reduce leaching of non-hyperaccumulated metals. J Hazard Mater 368:141-148

33. Luster J, Göttlein A, Nowack B, Sarret G (2009) Sampling, defining, characterising and modeling the rhizosphere-the soil science tool box. Plant Soil 321:457-482

34. Martin BC, Statton J, Siebers AR, Grierson PF, Ryan MH, Kendrick GA (2017) Colonizing tropical seagrasses increase root exudation under fluctuating and continuous low light. Limnol Oceanogr 63:381-391 
35. McGrath SP, Shen ZG, Zhao FJ (1997) Heavy metal uptake and chemical changes in the rhizosphere. Plant Soil 188:153-159

36. Ok YS, Kim SC, Kim DK, Skousen JG, Lee JS, Cheong YW, Kim SJ, Yang JE (2011) Ameliorants to immobilize $\mathrm{Cd}$ in rice paddy soils contaminated by abandoned metal mines in Korea. Environ Geochem Health 33:23-30

37. Römkens P, Bouwman L, Japenga J, Draaisma C (2002) Potentials and drawbacks of chelateenhanced phytoremediation of soils. Environ Pollut 116:109-121

38. Shokrollahi S, Ghanati F, Sajedi RH, Shari M (2018) Possible role of iron containing proteins in physiological responses of soybean to static magnetic fi eld 226, 163-171

39. Tang YT, Qiu RL, Zeng XW, Ying RR, Yu FM, Zhou XY (2009) Lead, zinc, cadmium hyperaccumulation and growth stimulation in Arabis paniculata Franch. Environ Exp Bot 66:126-134

40. Tao Q, Zhao J, Li J, Liu Y, Luo J, Yuan S, Li B, Li Q, Xu Q, Yu X, Huang H, Li T, Wang C (2020) Unique root exudate tartaric acid enhanced cadmium mobilization and uptake in Cd-hyperaccumulator Sedum alfredii. J Hazard Mater 383:1-10

41. Teixeira da Silva JA, Dobránszki J (2016) Magnetic fields: how is plant growth and development impacted? Protoplasma 253:231-248

42. Wang G, Wang L, Ma F, You Y, Wang Y, Yang D (2020) Integration of earthworms and arbuscular mycorrhizal fungi into phytoremediation of cadmium-contaminated soil by Solanum nigrum L. $J$ Hazard Mater 389:1-11

43. Xiao W, Li D, Ye X, Xu H, Yao G, Wang J, Zhang Q, Hu J, Gao N (2017) Enhancement of Cd phytoextraction by hyperaccumulator Sedum alfredii using electrical field and organic amendments. Environ Sci Pollut Res 24:5060-5067

44. Xue SG, Chen YX, Reeves RD, Baker AJM, Lin Q, Fernando DR (2004) Manganese uptake and accumulation by the hyperaccumulator plant Phytolacca acinosa Roxb. (Phytolaccaceae) Environmental Pollution 131:393-399

45. Zhou Q, Li X, Lin Y, Yang C, Tang W (2019) Effects of copper ions on removal of nutrients from swine wastewater and on release of dissolved organic matter in duckweed systems. Water Res 158:171181

\section{Figures}




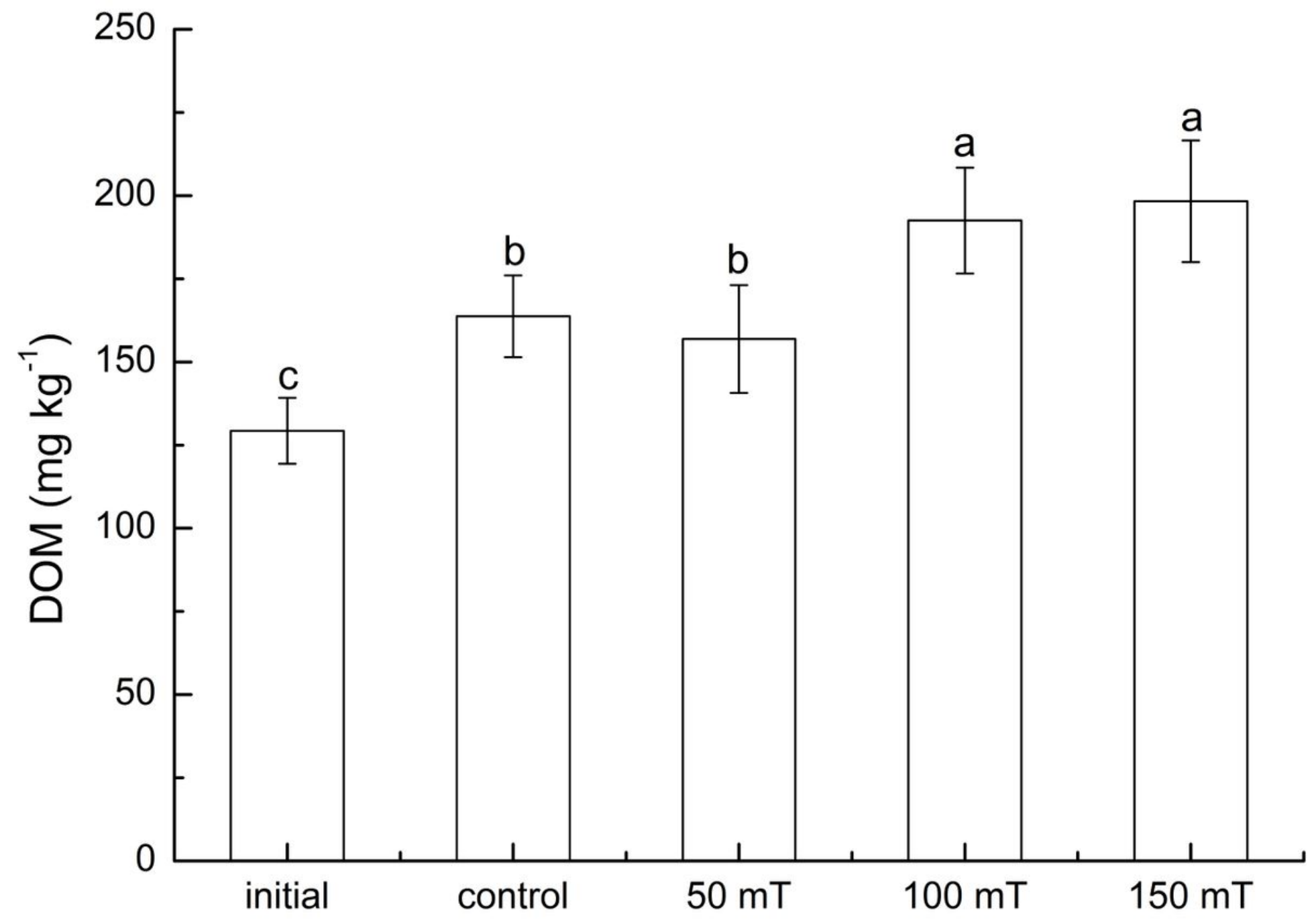

Figure 1

DOM concentrations in the rhizosphere of S. alfredii Different letters represent significant differences in DOM content $(p<0.05)$ evaluated by Fisher's LSD post-hoc tests in different treatments.
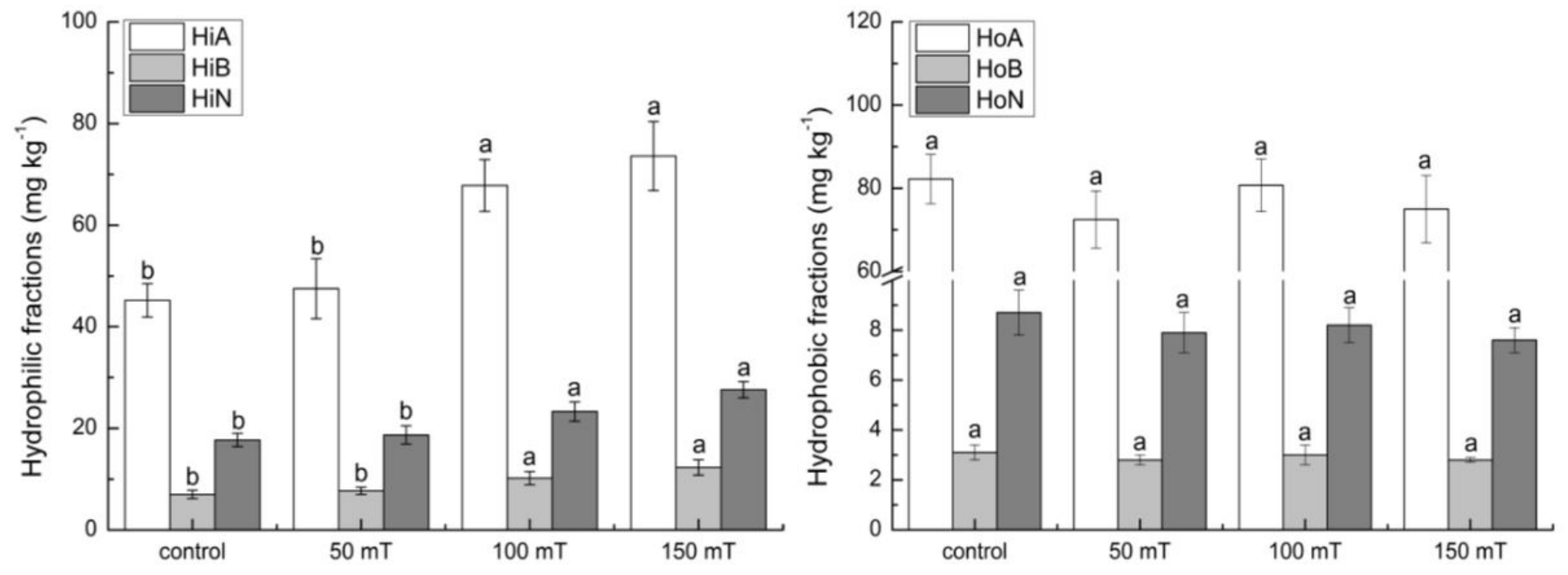

Figure 2 
DOM fractions in the rhizosphere of S. alfredii Different letters represent significant differences in DOM fractions $(p<0.05)$ evaluated by Fisher's LSD post-hoc tests in different treatments.

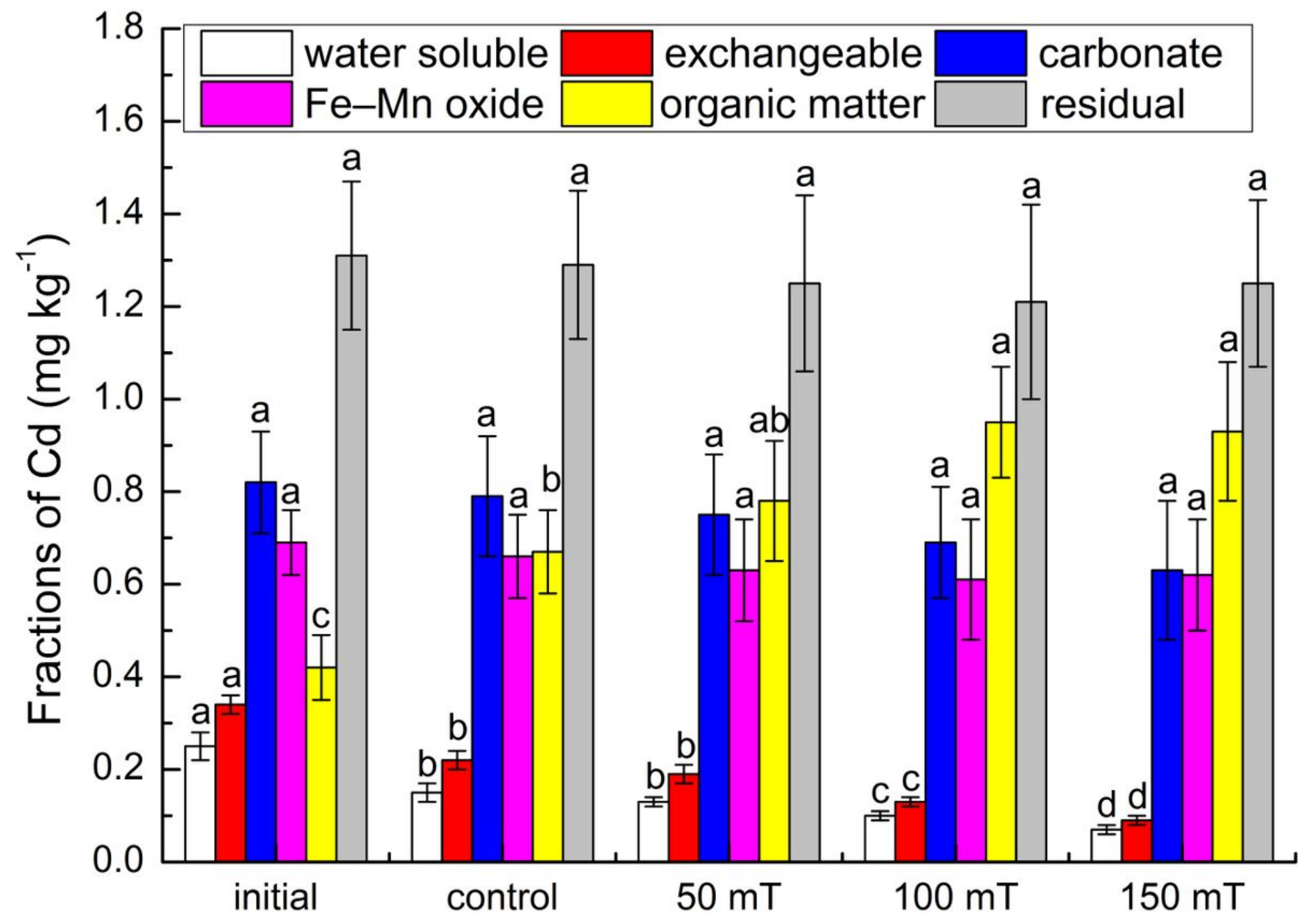

Figure 3

Chemical fractions of $\mathrm{Cd}$ in the rhizosphere of S. alfredii Different letters represent significant differences in Cd fractions $(p<0.05)$ evaluated by Fisher's LSD post-hoc tests in different treatments. 


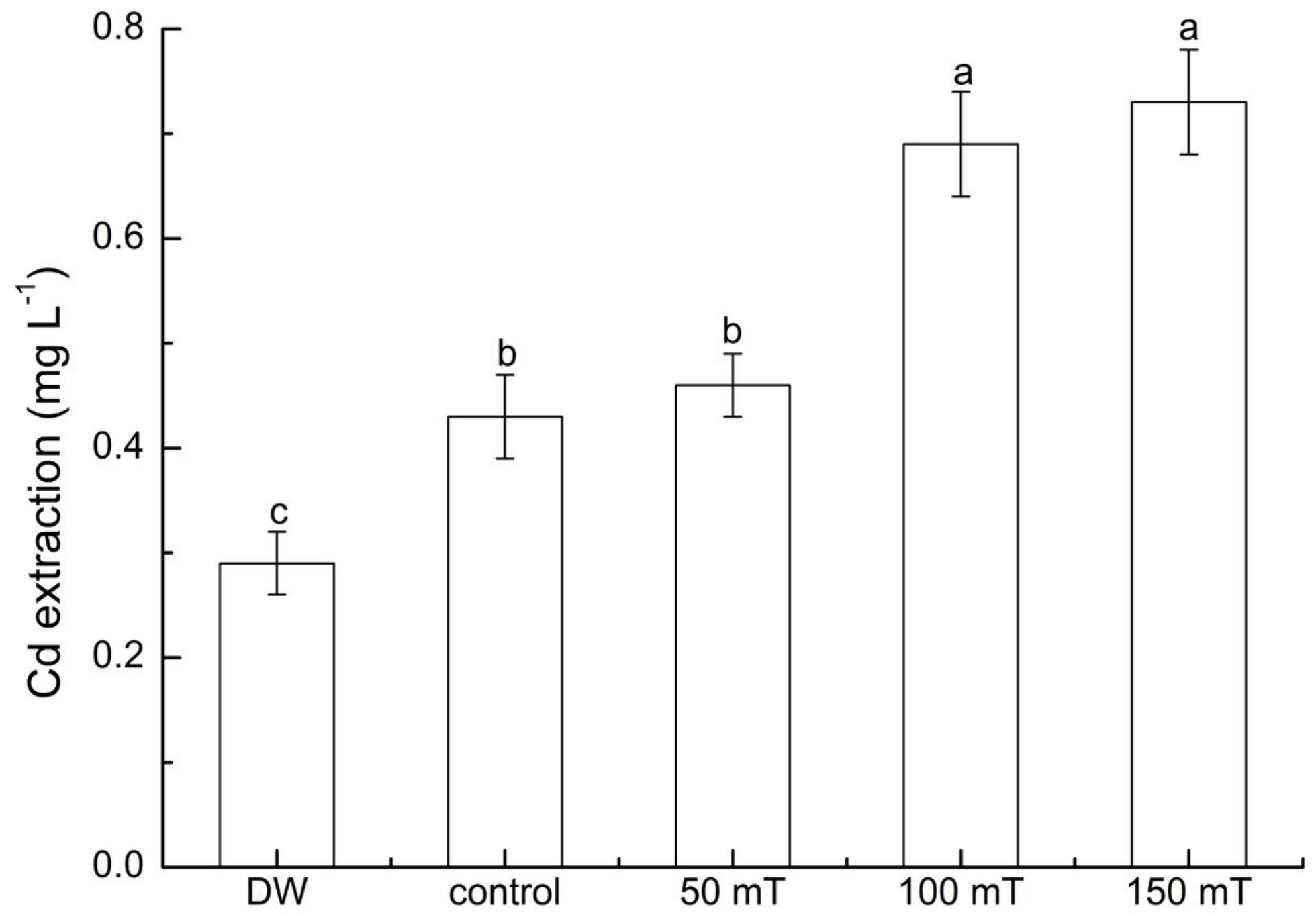

Figure 4

Cd extraction abilities of DOM in different treatments Different letters represent significant differences in Cd extraction $(p<0.05)$ evaluated by Fisher's LSD post-hoc tests in different treatments. 